\begin{tabular}{|l|c|c|c|c|c|}
\hline J. Tek. Ling & Vol.11 & No.1 & Hal. 27 - 32 & Jakarta, Januari 2010 & ISSN 1441-318X \\
\hline
\end{tabular}

\title{
KRETERIA DESAIN FOTOBIOREAKTOR SISTEM AIRLIFT REACTOR
}

\author{
Arif Dwi Santoso, Abdil H. S dan Diyono \\ Peneliti di Bidang Oseanografi Biologi \\ Badan Pengkajian dan Penerapan Teknologi
}

\begin{abstract}
Abstraks
Global warming has become an increasingly important issue around the world today due to the rise of anthropogenic greenhouse gases emission, which gives several negative impacts on human life.

There are some techniques have been studied and assessed i.e. physical mechanism by injected $\mathrm{CO}_{2}$ to the geological formations, chemical mechanism with artificial tree technology and biological mechanism by increasing the primary production through iron enrichment in high nutrient-low chlorophyll (HNLC) waters as well as mixing of water column below the sea surface. Those technologies, which are well known as Carbon Capture Storage '(CCS) technology, are expected to be applied to reduce the concentration of anthropogenic $\mathrm{CO}_{2}$ in the atmosphere and to minimize the global warming.

The Center of Environmental Technology, Agency for the Assessment and Application of Technology (BPPT) will carry out a research concerning $\mathrm{CO}_{2}$ reduction by a phytoplankton culture in a photobioreactor in three years. The main objective of this research is to assess the $\mathrm{CO}_{2}$ uptake capability of tropical phytoplankton.

In this paper, we would showed the creteria and design to assembly a photobioreactor esspesially a air lift photobioreactor. To improve performance photobioreaktor, the materials included design criteria and the dynamics of fluids in fotobioreaktor have to considered propoerly. Other the hand, the selection of the most productive species and selection of appropriate media and economically also important to be done.
\end{abstract}

Keywords: global warming, creteria and design, greenhouse gas, air lift photobioreactor

\section{PENDAHULUAN}

Meningkatnya konsentrasi gas karbon dioksida $\left(\mathrm{CO}_{2}\right)$ di atmosfer yang didominasi akibat dari aktivitas manusia menyebabkan berbagai dampak negatif bagi lingkungan manusia itu sendiri. Berbagai upaya telah dilakukan untuk melakukan mitigasi terhadap pengaruh buruk peningkatan $\mathrm{CO}_{2}$ di atmosfir bumi, salah satunya yang sedang naik daun adalah pengunaan fitoplankton sebagai penyerap gas $\mathrm{CO}_{2}$ secara alami ${ }^{1}$.

Di Badan Pengkajian dan Penerapan
Teknologi (BPPT) pada tahun 2008, telah dilakukan uji coba kultur fitoplankton air tawar dan air laut pada sebuah fotobioreaktor airlift sistem batch. Pada uji coba ini konsentrasi $\mathrm{CO}_{2}$ sekitar $12 \%$ dapat diturunkan dalam waktu sekitar 7 hari oleh species Chlorella sp., dan sekitar 13 hari oleh species Chaetoceros sp.

Padatahun2009ini ujicobapenyerapan gas $\mathrm{CO}_{2}$ dengan kultur fitoplankton dalam fotobioreaktor akan dilanjutkan dengan 
sistem kontinyu, diharapkan produktifitas dan efektivitas fotobioreaktor bias ditingkatkan sehingga pada tahun 2010 nanti produk desain fotobioreaktor dapat diaplikasikan dalam instalasi industry skala besar. Untuk memperbaiki performance fotobioreaktor, pemilihan spesies dan media tumbuh fitoplankton maka dilakukan studi literatur secara menyeluruh. Materi-materi yang menjadi target antara lain kreteria desain dan dinamika fluida dalam fotobioreaktor, pemilihan spesies yang paling produktif dan pemilihan media yang tepat dan ekonomis.

\section{PHOTOBIOREAKTOR}

\subsection{Pendahuluan}

Fotobioreaktor (PBR) adalah sebuah wadah tertutup (terbebas dari kontak udara luar) untuk membiakkan sel bakteri/ fitoplankton dimana energi disuplay ke dalam wadah melalui energi cahaya ${ }^{2}$. Secara umum faktor utama yang diperhitungkan dalam perakitan suatu fotobioreaktor ada dua hal yaitu penerapan biaya operasional yang efektif dan konsistensi dalam menjaga kualitas biomass yang dihasilkan.

Pada awalnya PBR difungsikan untuk memproduksi suatu biomass, namun dalam perkembangannya kemampuan PBR menjadi multifunction antara lain $^{21}$ :

a. Menghasilkan pigmen, fatty acids, dan bioactive molecules

b. Wadah budidaya di outer space

c. Menghilangkan beberapa senyawa toxic dan $\mathrm{B}_{3}$ dalam air

d. Menghasilkan gas dalam cyanobacteria

e. Menyerap gas $\mathrm{CO}_{2}$

f. Memproduksi gas hydrogen

\subsection{Airlift Reaktor (ALR)}

Perbedaan utama antara reaktor jenis airlift reactor (ALR) dengan jenis lain seperti jenis bubble colums adalah dari jenis aliran media di dalam reaktor ${ }^{(1),(3)}$. Pada reaktor bubble column biasanya gas diinjeksi dari dasar reaktor dan menghasilkan pergerakan dari percampuran gas dan media secara tak beraturan dari dasar ke atas reaktor. Sedang pada ALR reaktor, sirkulasi utama gas dan media ditentukan oleh desain reaktor yang mempunyai saluran pencampuran ke atas dan ke bawah. Saluran ini menentukan kecepatan dan tercampurnya antara media dan gas, sehingga ukuran diameter dan tinggi saluran sangat tergantung pada kepentingan pembuatan reaktor.

\section{Morfologi Reaktor Airlift}

Reaktor airlift mempunyai bagianbagian utama yang mempengaruhi pola aliran media yang diperhitungkan dalam perakitannya (Gambar 1) antara lain:

- $\quad$ Top Clearance $(\mathrm{Cl})$ : jarak antara penutup reaktor atas dengan media

- Area Ratio (Ad/Ar) : perbandingan antara luas permukaan downcomer dengan riser

- Tinggi Reaktor (h) : tinggi antara dasar dan penutup atas reaktor

- Bottom clearance (Cb): jarak antara dasar reaktor dengan tube gas input

\section{Keuntungan Reaktor Airlift}

Untuk tujuan peningkatan pertumbuhan biomass mikroorganisme atau fitoplankton, reaktor airlift memiliki beberapa kelebihan dibanding reaktor jenis stirrer tank atau jenis bubble coloums.

Beberapa keuntungan reaktor jenis ini antara lain ${ }^{1,2,3)}$ :

1. Proses pencampuran dan pergerakan media dalam reaktor dilakukan simultan dengan injeksi gas sehingga tidak memerlukan suplay energi lagi.

2. Pencampuran gas dan media merata ke segenap ruang dalam reaktor, sehingga distribusi biomass, nutrien dan gas-gas merata. Terdistribusinya 


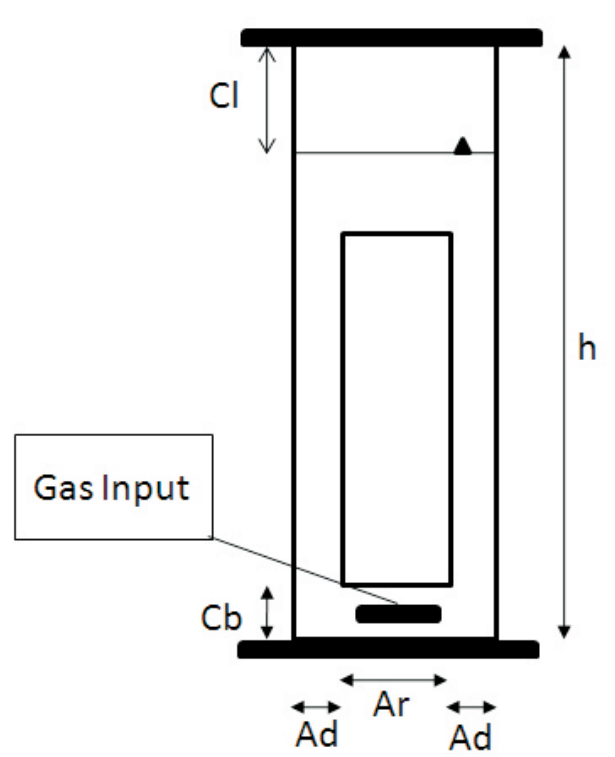

Gambar 1. Komponen Reaktor Airlift

secara sempurna marerial dalam reaktor juga akan mengurangi stratifikasi suhu, photoinhibition dan menjaga sel biomass selalu dalam kondisi tersuspensi.

3. Sel biomass tidak akan terganggu oleh gerakan mekanisme stirrer seprti yang terjadi pada reaktor jenis stirrer tank.

\subsection{Kreteria Desain}

Untuk mengakomodasi beberapa multi fungsi PBR di atas, PBR perlu didesain dan dirakit dengan mempertimbangkan beberapa parameter penting. Banyak model dan bentuk PBR yang telah dikembangkan mulai dari tubular hingga cylinder system. Dari bermacam-macam model PBR tersebut, dasar pertimbangan yang sering menjadi acuan antara lain: bagaimana PBR dapat mensuplai cahaya, bagaimana mensirkulasi media dalam PBR, bagaimana mensuplai gas $\mathrm{CO}_{2}$ dan menyerap $\mathrm{O}_{2}$ dan bagaimana mengontrol $\mathrm{pH}$ dan temperature dalam PBR. Berikut ini disajikan rangkuman beberapa konfigurasi parameter yang sering mendapat perhatian dalam pendisainan suatu PBR :

\section{a) Cahaya}

Pencahayaan murupakan parameter yang sangat penting dalam pendisainan dan perakitan suatu PBR. Meski demikian parameter ini sangat sulit ditentukan kisaran yang paling ideal untuk peruntukan suatu PBR. Pencahayaan bisa diterapkan secara terus menerus sepanjang hari atau berdasarkan periode tertentu (light-dark cycles) tergantung dari biologi spesies yang dibiakkan dalam PBR. Beberapa alga ada yang menyukai pencahayaan yang terbatas, ada pula yang bersifat phototrophs yang memerlukan intensitas pencahayaan yang tinggi dan terus menerus. Secara umum, fitoplankton bersifat phototroph sehingga tingginya tingkat pencahayaan akan meningkatkan pertumbuhannya ${ }^{11}$.

Tabel1. Peneliti dan Aplikasi Penggunaan cahaya dalam PBR:

\begin{tabular}{|l|l|l|l|}
\hline No & Peneliti & Intensitas cahaya yg digunakan & Keterangan \\
\hline 1 & Wu and Merchuk, 2002 ${ }^{3)}$ & $250 \mathrm{uE} \cdot \mathrm{m}^{-2} \mathrm{~s}^{-1}$ & Out door \\
\hline 2 & Minoo et al., 19914) & $1-2 \mathrm{~mW} / \mathrm{cm}^{2}$ & Out door \\
\hline 3 & Ancien et al., 19981) & $185 \mathrm{uE} \cdot \mathrm{m}^{-2} \mathrm{~s}^{-1}$ & Out door \\
\hline 4 & Doucha, $2005^{5)}$ & $300-380 \mathrm{~W} \cdot \mathrm{m}^{-2}$ & Out door \\
\hline
\end{tabular}




\section{b) Sirkulasi Media dan Gas dalam PBR}

Sirkulasi media dan gas juga merupakan parameter penting yang dipertimbangkan dalam perakitan PBR. Fungsi utama sirkulasi dalam PBR antara lain :

1. menjaga sel alga selalu dalam kondisi suspended

2. mengurangi stratifikasi suhu yang tinggi

3. membantu distribusi nutrien

4. meningkatkan perpindahan gas/ menambah permukaan reaksi antara gas dan media

5. mengurangi mutual shading dan photoinhibition

Beberapa variasi sirkulasi media yang sering diaplikasikan dalam PBR antara lain :

a. menggunakan stirerred-tank

b. bubling udara secara langsung

c. bubling udara secara tidak langsung dengan airlift system

d. static mixer

Sirkulasi yang kita berikan dalam PBR harus disesuaikan dengan kemampuan adaptasi fitoplankton yang kita pelihara. Tingginya kecepatan bubling udara dalam PBR akan menyebabkan stress pada fitoplankton. Oleh karena itu kecepatan bubling udara ini harus ditentukan seoptimal mungkin bagi kehidupan fitoplankton. Hubungan antara kecepatan bubling udara dengan kooefisein transfer massa air (kLa) menjadi topik yang menarik untuk dipelajari lebih lanjut. Penetapan rasio antara kecepatan bubling udara dengan kooefisein transfer massa air yang tepat akan meningkatkan produktivitas PBR. Beberapa pengalaman peneliti dalam penerapan kecepatan bubling dalam PBR disajikan dalam Tabel 2.

Aplikasi injeksi gas $\mathrm{CO}_{2}$ dalam PBR sering dilakukan dalam upaya selain untuk meningkatkan produktivitas PBR juga dalam rangka misi lingkungan yakni mengurangi gas $\mathrm{CO}_{2}$. Prinsip utama yang harus diperhatikan dalam injeksi gas tersebut adalah mengusahakan agar proses injeksi yang dilakukan tidak menurunkan $\mathrm{pH}$ media. Untuk itu strategi yang harus dilakukan adalah meningkatkan kegiatan mengontrol $\mathrm{pH}$ media dalam PBR.

Beberapa variabel mempengaruhi sirkulasi media antara $\left(\right.$ lain $^{3}$ :

Riser. Pada ruang riser, gas dan liquid mengalir ke atas, dan kecepatan gas pada umumnya lebih tinggi daripada kecepatan liquid, kecuali pada keadaan homogenous flow dimana gas dan liquid mengalir dalam kecepatan yang sama. Hal ini terjadi bila bubble yang sangat kecil terbentuk.

Downcomer. Pada ruang downcomer, media mengalir dan membawa bubble

Tabel 2. Peneliti dan Penerapan Kecepatan Bubling dalam PBR ${ }^{2)}$

\begin{tabular}{|l|l|l|l|}
\hline No & Peneliti & Kecepatan bubling udara dan kLa & Keterangan \\
\hline 1 & Contreas et al, 1998 & $\mathrm{V}=0,055 \mathrm{~m} \cdot \mathrm{s}^{-1} \mathrm{kLa}=0.02 \mathrm{~s}^{-1}$ & Out door \\
\hline 2 & Ogbonna, 1998 & $\mathrm{kLa}=0.02 \mathrm{~s}^{-1}$ & Out door \\
\hline 3 & Merchuk, 2000 & $\mathrm{V}=0,02 \mathrm{~m} \cdot \mathrm{s}^{-1}$ & Out door \\
\hline 4 & Zhang et al, 2002 & $\mathrm{V}=0,024 \mathrm{~m} \cdot \mathrm{s}^{-1}$ & Out door \\
\hline 5 & Acien, 2001 & $\mathrm{V}=0,25 \mathrm{~m} \cdot \mathrm{s}^{-1} \mathrm{kLa}=0.006 \mathrm{~s}^{-1}$ & Out door \\
\hline 6 & Camacho, 1999 & $\mathrm{~V}=0,16 \mathrm{~m} \cdot \mathrm{s}^{-1} \mathrm{kLa}=0.014 \mathrm{~s}^{-1}$ & Out door \\
\hline
\end{tabular}


ke bawah. Agar kondisi ini selalu terjadi, kecepatan media harus lebih besar dari kecepatan mengambang (free rise velocity) dari bubble. Jika kecepatan gas input kecil; drag force yang dihasilkan akan tidak mencukupi untuk melawan buoyancy, akibatnya terjadi feed back loop dalam downcomer dan terjadi stratifikasi bubble. Diperlukan gas input dan rasio Ar/Ad yang tepat untuk membentuk aliran yang uniform dan tipe aliran yang diinginkan.

Gas Separator. Disain geometris dari separator akan mempengaruhi banyaknya bubble yang lepas dari riser. Disain gas separator yang diperlebar bertujuan untuk mengurangi kecepatan liquid dan menampung bubble yang terlepas.

Viskositas. Semakin rendah viskositas liquid, akan mempengaruhi nilai gas hold up yang cenderung semakin tinggi. Hal ini dapat disebabkan karena free rise velocity yang semakin meningkatkan nilai residence time.

Top Clearance. Dari percobaan yang dilakukan merchuk, et all, menunjukkan hasil, semakin rendah nilai top clearance, nilai gas hold up akan cenderung semakin meningkat.

\section{c) Temperatur dan $\mathrm{pH}$}

Selain gas $\mathrm{CO}_{2}$ dan $\mathrm{O}_{2}, \mathrm{pH}$ dan temperatur adalah parameter penting yang harus selalu diukur dan dikontrol selama pembiakan dalam PBR berlangsung. Banyak metode yang digunakan dalam mengontrol dinamika parameter $\mathrm{pH}$ dan temperatur, baik yang automatic maupun manual. Metode yang sering dilakukan antara lain penggunaan pendinginan eksternal dalam PBR, menggunakan water jacket, pengunaan kolam pendingin dan sirkulasi air di luar PBR2).

\section{d) Sterilisasi}

Banyak fitoplankton phototrophs tumbuh dengan kontaminasi bakteri dan jamur. Permasalahan ini merupakan hal serius yang sering terjadi pada kegiatan operasional PBR di luar ruangan. Di sisi lain PBR kita yang terbuat dari acrylic dan memiliki ukuran yang besar tidak memungkinkan untuk dimasukkan dalam autoclave. Untuk itu pemilihan metode sterilisasi dan bahan yang digunakan harus tepat dan efisien. Salah satu pilihan metode sterilisasi yang memungkinkan adalah metode bleach., sementara pompa udara, probe analyzer dan peralatan lain dapat dicegah terdapat kontaminasi bakteri dan jamur dengan penggunaan filter yang baik.

\section{e) Strategi Operasional}

Strategi operasional yang umum dilakukan dalam pembiakan fitoplankton dalam PBR antara lain:

1. Pengukuran secara berkala terhadap parameter $\mathrm{CO}_{2}, \mathrm{O}_{2}$, pH dan Temperatur. Ke-empat konsentrasi parameter ini harus dikontrol secara terus menerus untuk memastikan konsentrasinya selalu dalam konsentrasi yang diharapkan bagi pertumbuhan fitoplankton yang dibiakkan.

2. Jaminan kepastian pasokan media dalam PBR

3. Pemanenan biomass secara berkala dengan satuan $\mathrm{L}^{-1} \mathrm{jam}^{-1}, \mathrm{~L}^{-1}$ hari-1 


\section{KESIMPULAN}

Dari rangkuman studi literatur tentang kreteria photobioreaktor sistem air lift di atas, beberapa referensi di bawah ini diharapkan dapat membantu kegiatan perakitan dan kegiatan operasional PBR sistem ALR adalah :

1. Untuk membentuk homogenous bubbly flow, Inlet superficial gas velocity pada riser sebaiknya dibawah sekitar $0.05 \mathrm{~m} / \mathrm{s}$.

2. Kecepatan gas injeksi dalam reaktor sekitar $0.334 \mathrm{~cm} / \mathrm{s}$

3. Penetrasi cahaya matahari di sekitar reaktor sekitar $250 \mathrm{uE} . \mathrm{m}^{-2} \mathrm{~s}^{-1}$

4. Tinggi reaktor sekitar $1.0 \mathrm{~m}$

5. Perbandingan antara ruang riser dan downcomer adalah 0.5

\section{DAFTAR PUSTAKA}

1. Acien et al., 2000. Scale-up of tubular photobioreactors. . Journal of Applied Phycology (2005)12: 355-368

2. Behren P.W., 2005. Algal Culturing Techniques. Photobioreactors and Fermentors: The light and Dark Sides of Growing Algae. Academic press. 189-199p.

3. Wu X., Merchuk J.C., 2004. Simulation of algae growth in a bench scale internal loop airlift reactor. Chemical Engineering Science 59 (2004) 28992912

4. Minoo Javanmardian and Benhard O. P., 1991. High-Density Photoautotrophic Algal Cultures ; Design, Construction, and Operatin of a Novel Photobioreactor system. Biotechnology and Bioengineering, Vol. 38, pp 1182-1189.

5. Doucha, et al., 2005. Utilization of flue gas for cultivation of microalgae (Chlorella sp.) in an outdoor open thin-layer photobioreactor. Journal of Applied Phycology (2005)17:403412 